\title{
Triple infection with Cryptococcus, varicella- zoster virus, and Mycobacterium abscessus in a patient with anti-interferon-gamma autoantibodies: a case report
}

\author{
Pongprueth Rujirachun ${ }^{1}$, Jirath Sangwongwanich ${ }^{2}$ and Methee Chayakulkeeree ${ }^{3^{*}}$ (D)
}

\begin{abstract}
Background: The most common infection in patients positive for anti-interferon-gamma autoantibodies (anti-IFN- $\gamma$ AAbs) is disseminated nontuberculous mycobacterial (dNTM) infection. Here, we report a rare case of triple infection caused by Cryptococcus, varicella-zoster virus (VZV), and nontuberculous mycobacterium in a patient with anti-IFN- $\gamma$ AAbs.

Case presentation: A 53-year-old Thai man presented with a progressively enlarging right cervical mass with low-grade fever and significant weight loss for 4 months. He also developed a lesion at his left index finger. A biopsy of that lesion showed granulomatous inflammation with yeast-like organisms morphologically consistent with cryptococcosis. Serum cryptococcal antigen was positive. Histopathology of a right cervical lymph node revealed chronic granulomatous lymphadenitis, and the lymph node culture grew Mycobacterium abscessus. One month later, he complained of vision loss in his left eye and subsequently developed a group of painful vesicles at the right popliteal area of S1 dermatome. Lumbar puncture was performed and his cerebrospinal fluid was positive for VZV DNA. His blood test for anti-HIV antibody was negative. Anti-IFN- $\gamma$ AAbs was positive, but test for anti-granulocyte-macrophage colony-stimulating factor autoantibodies (antiGM-CSF AAbs) was negative. He was treated with amphotericin B plus fluconazole for cryptococcosis; a combination of amikacin, imipenem, azithromycin, and levofloxacin for dNTM infection; and, intravenous acyclovir for disseminated VZV infection. After treatment, our patient's fever and cervical lymphadenopathy were subsided, and his vision and visual acuity were both improved.
\end{abstract}

Conclusions: This is the first case of triple infection with cryptococcosis, VZV, and dNTM in a patient who tested positive for anti-IFN- $\gamma$ AAbs and negative for anti-GM-CSF AAbs. This case will increase awareness and heighten suspicion of these infections in patients with the described presentations and clinical characteristics, and this will accelerate diagnosis and treatment.

Keywords: Anti-interferon-gamma autoantibody, Cryptococcus, Varicella-zoster virus, Nontuberculous mycobacteria, Mycobacterium abscessus

\footnotetext{
* Correspondence: methee.cha@mahidol.ac.th

${ }^{3}$ Division of Infectious Diseases and Tropical Medicine, Department of

Medicine, Faculty of Medicine Siriraj Hospital, Mahidol University, 2 Wanglang

Road, Bangkoknoi, Bangkok 10700, Thailand

Full list of author information is available at the end of the article
}

(c) The Author(s). 2020 Open Access This article is licensed under a Creative Commons Attribution 4.0 International License, which permits use, sharing, adaptation, distribution and reproduction in any medium or format, as long as you give appropriate credit to the original author(s) and the source, provide a link to the Creative Commons licence, and indicate if changes were made. The images or other third party material in this article are included in the article's Creative Commons licence, unless indicated otherwise in a credit line to the material. If material is not included in the article's Creative Commons licence and your intended use is not permitted by statutory regulation or exceeds the permitted use, you will need to obtain permission directly from the copyright holder. To view a copy of this licence, visit http://creativecommons.org/licenses/by/4.0/. The Creative Commons Public Domain Dedication waiver (http://creativecommons.org/publicdomain/zero/1.0/) applies to the data made available in this article, unless otherwise stated in a credit line to the data. 


\section{Background}

Adult-onset immunodeficiency with anti-interferongamma autoantibodies (anti-IFN- $\gamma$ AAbs) is a newly recognized immunodeficiency syndrome that is predominantly reported in Southeast Asians. The most common infection in patients with this condition is disseminated nontuberculous mycobacterial (dNTM) infection [1]. Other opportunistic infections, such as varicella-zoster virus (VZV) infection or cryptococcosis, may occur in patients with anti-IFN- $\gamma$ AAbs as unusual sequential or concomitant infections [2]. However, simultaneous multiple infections in patients with anti-IFN- $\gamma$ AAbs are very rare. In this report, we present a patient positive for
anti-IFN- $\gamma$ AAbs, but negative for anti-granulocytemacrophage colony-stimulating factor autoantibodies (anti-GM-CSF AAbs) who had triple infection with Cryptococcus, VZV, and Mycobacterial abscessus.

\section{Case presentation}

A 53-year-old man presented to a private hospital in March 2018 with a progressively enlarging right cervical mass, low-grade fever, and significant weight loss for 4 months. Physical examination revealed right cervical lymphadenopathy. Needle aspiration of an enlarged lymph node was performed and the findings were suggestive of lymphadenitis without evidence of malignancy.
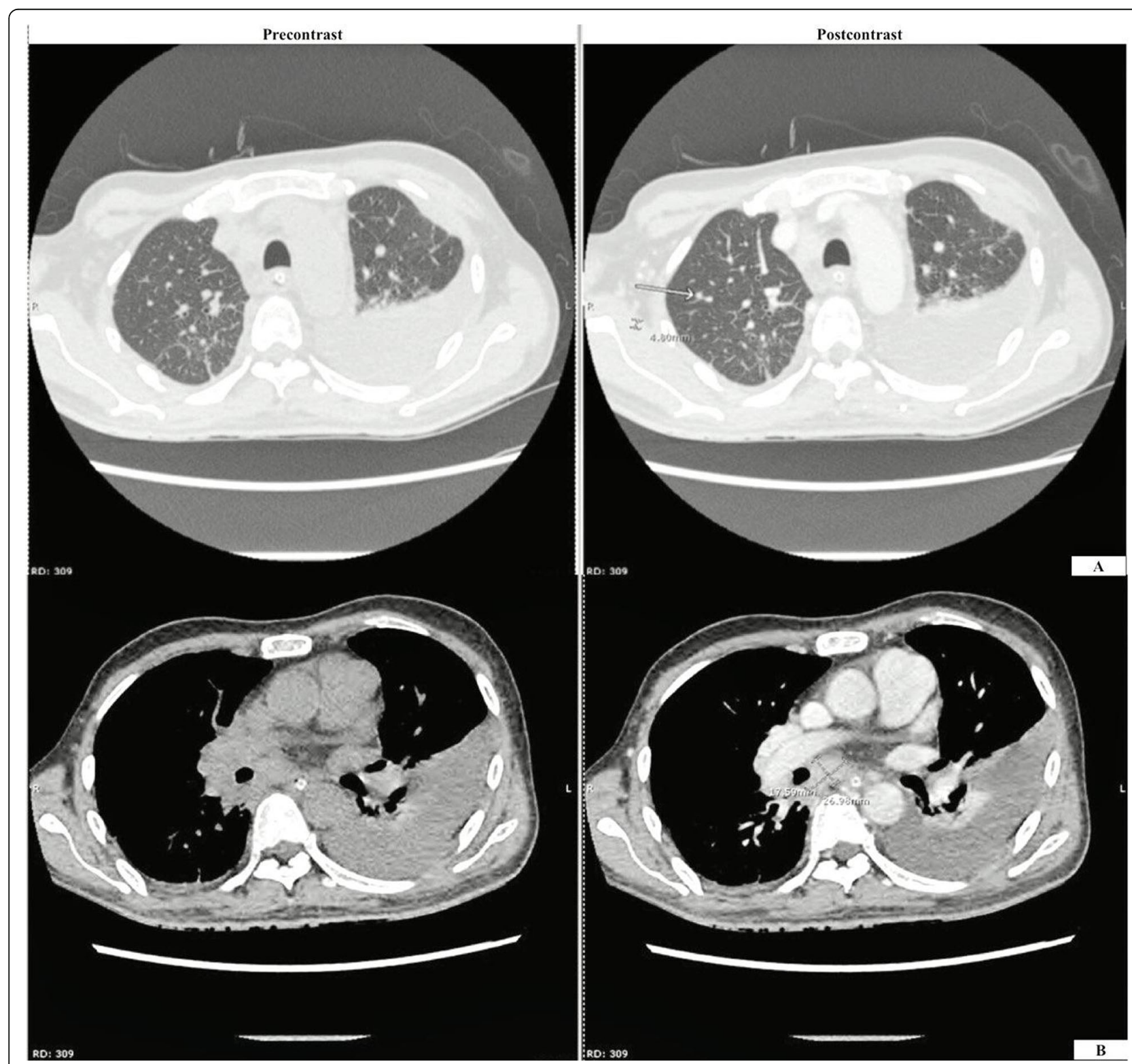

Fig. 1 CT chest with contrast showed a $4.5 \mathrm{~mm}$ non-calcified nodule at the RUL (a) and multiple mediastinal mass lymphadenopathies measuring up to $2.6 \times 1.8 \mathrm{~cm}$ at the subcarinal region $(\mathbf{b})$ 
Four months later, he returned to the same hospital with progressive fatigue. Physical examination showed mild anemia, and a chronic ulcer at his left index finger was noted. Complete blood count revealed hemoglobin $9.0 \mathrm{~g} / \mathrm{dL}$, hematocrit $28.2 \%$, white blood cell (WBC) count $9.9 \times 10^{9 /} \mathrm{L} \quad(74.1 \%$ neutrophils, $14.6 \%$ lymphocytes, $3.5 \%$ monocytes, $6.9 \%$ eosinophils, and $0.9 \%$ basophils), and a platelet count of $207 \times$ $10^{9} /$ L. Blood test for anti-HIV antibody was negative. Right paratracheal mass was suspected from the chest radiograph. Chest computerized tomography showed a non-calcified nodule $(4.5 \mathrm{~mm}$ in diameter) at the right upper lung with enlargement of multiple mediastinal lymph nodes (Fig. 1). Biopsy of a right cervical lymph node revealed chronic granulomatous lymphadenitis. Tuberculous lymphadenitis was suspected and empirical anti-tuberculosis therapy was commenced with rifampicin $600 \mathrm{mg} /$ day, isoniazid $300 \mathrm{mg} /$ day, pyrazinamide $1.6 \mathrm{~g} /$ day, and ethambutol $1.1 \mathrm{~g} /$ day. During admission, he developed dyspnea and his follow-up chest radiograph revealed left pleural effusion (Fig. 2). Thoracentesis was performed and the pleural fluid profile revealed a total cell count of $2.00 \times 10^{11} / \mathrm{L}, \mathrm{RBC}$ count of $0.00 \times 10^{11} / \mathrm{L}$, WBC count of $2.00 \times 10^{9} / \mathrm{L} \quad(25 \%$ neutrophils, $70 \%$ lymphocytes, $2 \%$ mesothelial cells, and 3\% macrophages), adenosine deaminase (ADA) $7.21 \mathrm{IU} / \mathrm{L}$, and cytology for malignancy was negative. The patient was then referred to our center for further investigation and treatment. The Faculty of Medicine Siriraj Hospital, Mahidol University is a 2300-bed national tertiary referral hospital that is located in Bangkok, Thailand.
Upon arrival from the referring hospital, our patient's histopathological slides were reviewed. The biopsied tissue from his left index finger showed cryptococcosis with granulomatous reaction, and the biopsy from the right cervical lymph node showed chronic granulomatous inflammation with multiple minute foci and a small number of yeasts. Although fungal cultures from the left index finger, a right cervical lymph node, and blood were negative, serum cryptococcal antigen was positive by latex agglutination test (IMMY, Norman, OK, USA) with a titre of 1:32. Anti-IFN- $\gamma$ AAbs was sent and the result showed positive. Antibodies to IFN- $\gamma$ in serum were measured by in-house enzyme-linked immunosorbent assay (ELISA). The average optical density (OD) from two independent tests was greater than or equal to one, which is considered positive. The cut-off OD was determined using in-house data that was based on a comparison between a group of patients with this syndrome and more than 100 healthy controls. Anti-GMCSF AAbs was also sent, but that result was negative. Amphotericin B $0.7 \mathrm{mg} / \mathrm{kg} /$ day and fluconazole $800 \mathrm{mg} /$ day were given as induction therapy for 4 weeks, followed by oral fluconazole $800 \mathrm{mg}$ as consolidation treatment. After antifungal treatment, the lymphadenopathy was not improved. Accordingly, a repeat biopsy of a right cervical lymph node was performed to identify another causative organism. The culture of that biopsied lymph node revealed Mycobacterium abscessus. The patient was diagnosed as interferon-gamma autoantibodies with disseminated cryptococcosis and Mycobacterium abscessus infection. He was treated with a combination of amikacin

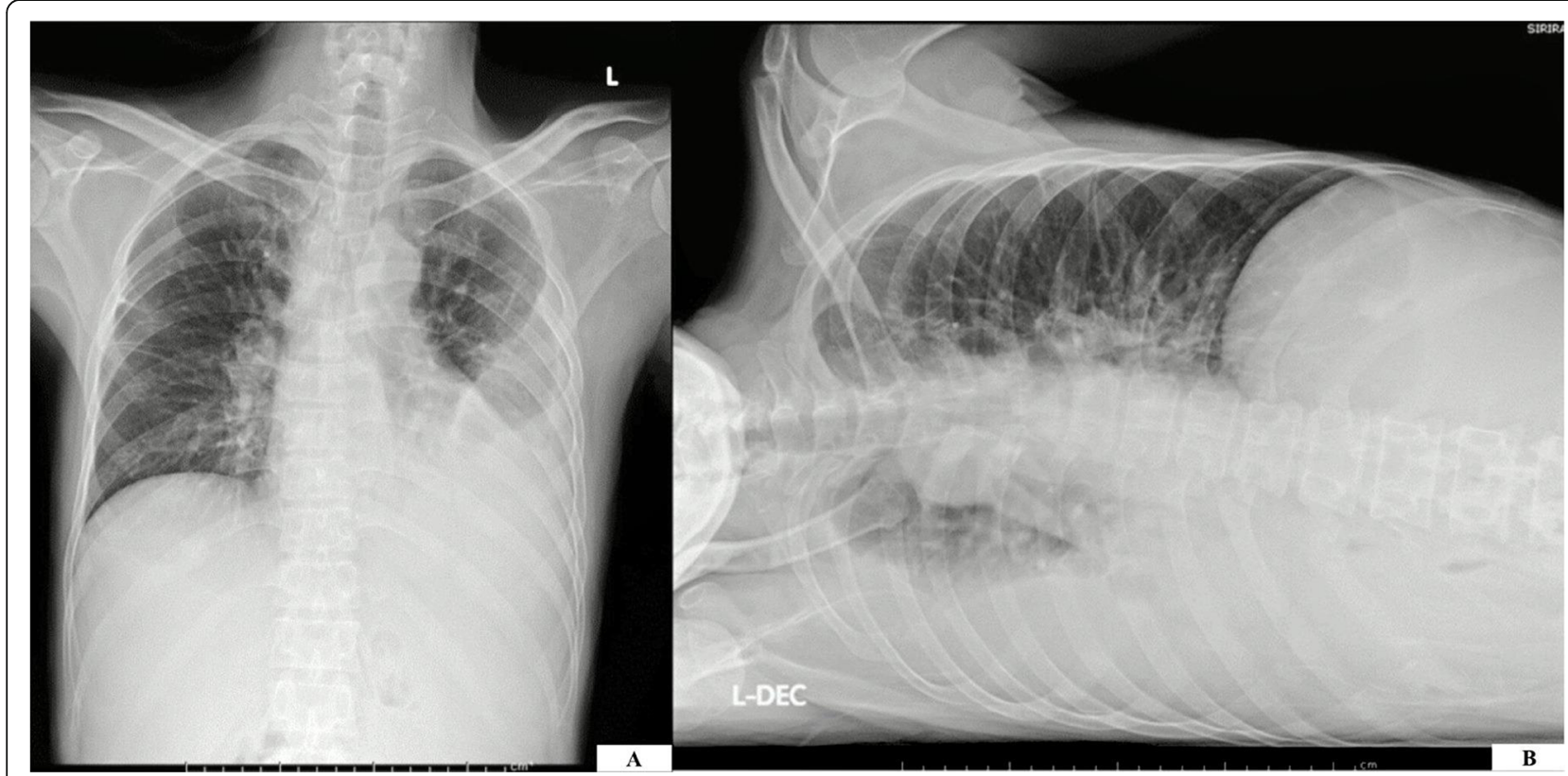

Fig. 2 Chest radiography with the patient in the PA upright (a) and left lateral decubitus (b) positions revealed massive left pleural effusion 
$750 \mathrm{mg} /$ day, imipenem $3 \mathrm{~g} /$ day, azithromycin $500 \mathrm{mg} /$ day, and levofloxacin $750 \mathrm{mg} /$ day. After antimicrobial treatment for 1 month, our patient's fever and cervical lymphadenopathy were subsided.

One month later, his eye examination showed bilateral optic disc swelling. Magnetic resonance imaging of orbits was performed and right optic nerve atrophy was identified (Fig. 3). No treatment was required. Two months later, he returned to Siriraj Hospital and complained of vision loss in his left eye. Ophthalmologic examination showed decreased visual acuity in both eyes, and bilateral atypical optic neuritis was suspected. Two days later, he developed a group of painful vesicles at the right popliteal area of S1 dermatome. Lumbar puncture revealed clear cerebrospinal fluid (CSF), a white blood cell count of $1 \mathrm{cell} / \mathrm{mm}^{3}$, no RBCs, protein $38 \mathrm{mg} / \mathrm{dL}$, and glucose $59 \mathrm{mg} / \mathrm{dL}$. CSF was sent for VZV-DNA detection by qualitative real-time polymerase chain reaction (PCR) kit (ARGENE ${ }^{\oplus}$; bioMérieux, Marcyl'Étoile, France), and the test showed a positive result. Even though the CSF did not present with lymphocytic pleocytosis, a positive CSF analysis for VZV-DNA by PCR is consistent with VZV infection of the central nervous system. In anti-IFN- $\gamma$ AAbs patients with visual loss, it is indicative of VZV optic neuritis. Moreover, he had a group of vesicles at the right popliteal area. Therefore, he was diagnosed disseminated VZV infection with optic neuritis. He was treated with intravenous acyclovir $1500 \mathrm{mg} /$ day. Two weeks after treatment, his vision and visual acuity were both improved.

\section{Discussion and conclusions}

Cryptococcus spp., VZV, and dNTM are intracellular opportunistic microorganisms that most often infect immunocompromised host, especially HIV-infected individuals. However, adult-onset immunodeficiency associated with cell-mediated immune defect should be suspected when these infections are found in patients who are not HIV-infected, and who did not receive immunosuppressive therapy. Adult-onset immunodeficiency due to anti-cytokine autoantibodies associated primarily with infectious manifestations is the most strongly suspected etiology in this patient [1]. Anti-IFN- $\gamma$ AAbs is a syndrome that is associated with disseminated mycobacterium infection, whereas anti-GM-CSF AAbs is mainly associated with cryptococcosis [3]. As such, requests were sent for both anti-IFN- $\gamma$ AAbs and anti-GM-CSF AAbs, and the results showed positive only for anti-IFN- $\gamma$ AAbs. It should be noted that GM-CSF is an important cytokine for inducing terminal differentiation of alveolar macrophages, and also for priming the function of neutrophils against intracellular organisms like cryptococcus [3]. In the context of a non-HIV patient with cryptococcosis, it is reasonable to test for AAbs to GM-CSF even though the clinical implication of overlap between anti-IFN- $\gamma$ and antiGM-CSF syndromes is currently unknown.

IFN- $\gamma$ is one of the key cytokines that plays an important role against intracellular pathogens, such as mycobacteria, VZV, and Cryptococcus. IFN- $\gamma$ is secreted by $\mathrm{T}$ lymphocytes, including CD4+ and CD8+, and NK cells. IFN- $\gamma$ can bind to specific receptor leading to activation
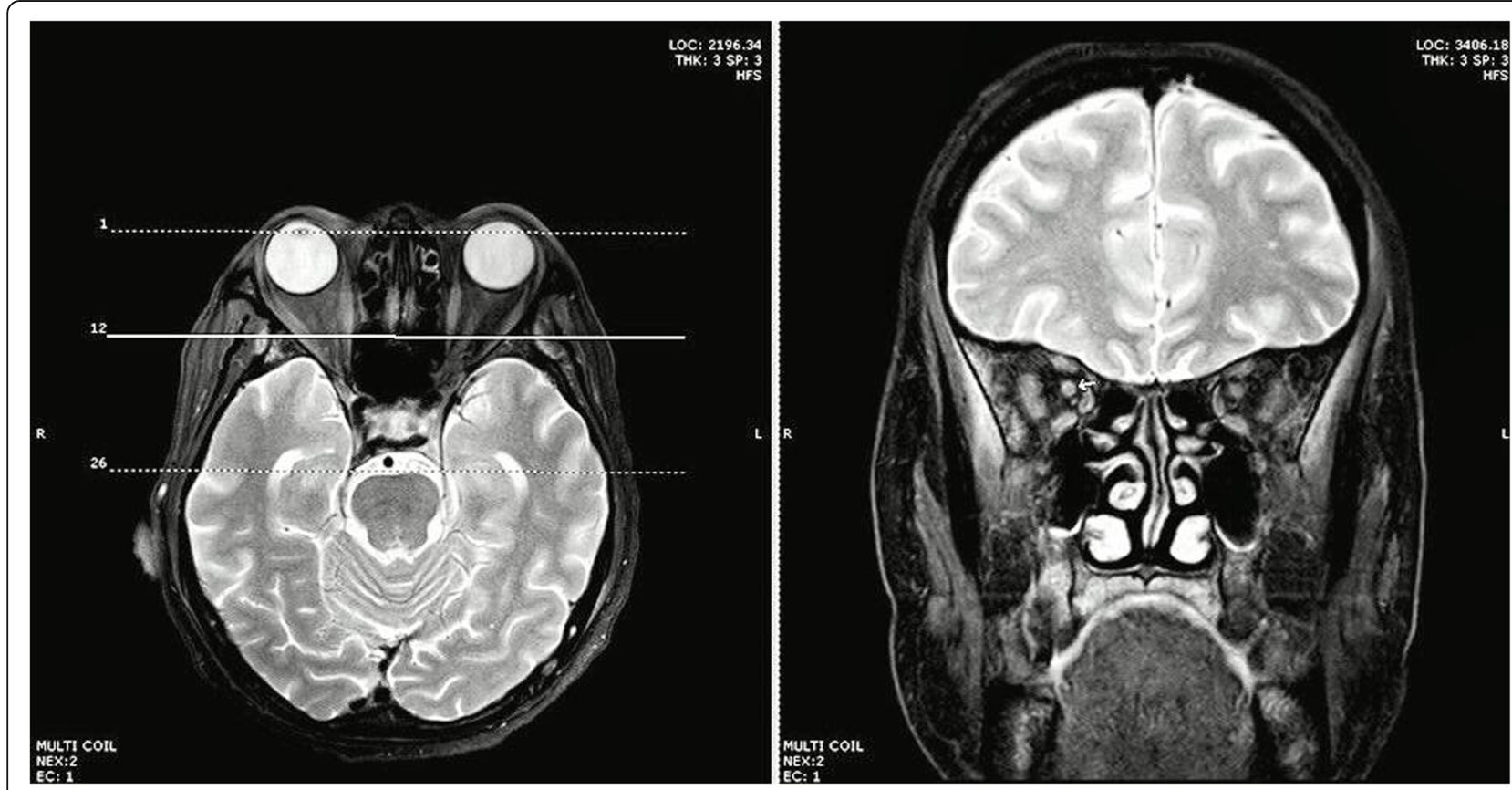

Fig. $3 \mathrm{MRI}$ orbits showed relatively small size and peripherally increased signal on T2W/FS at the right optic nerve without definite enhancement 


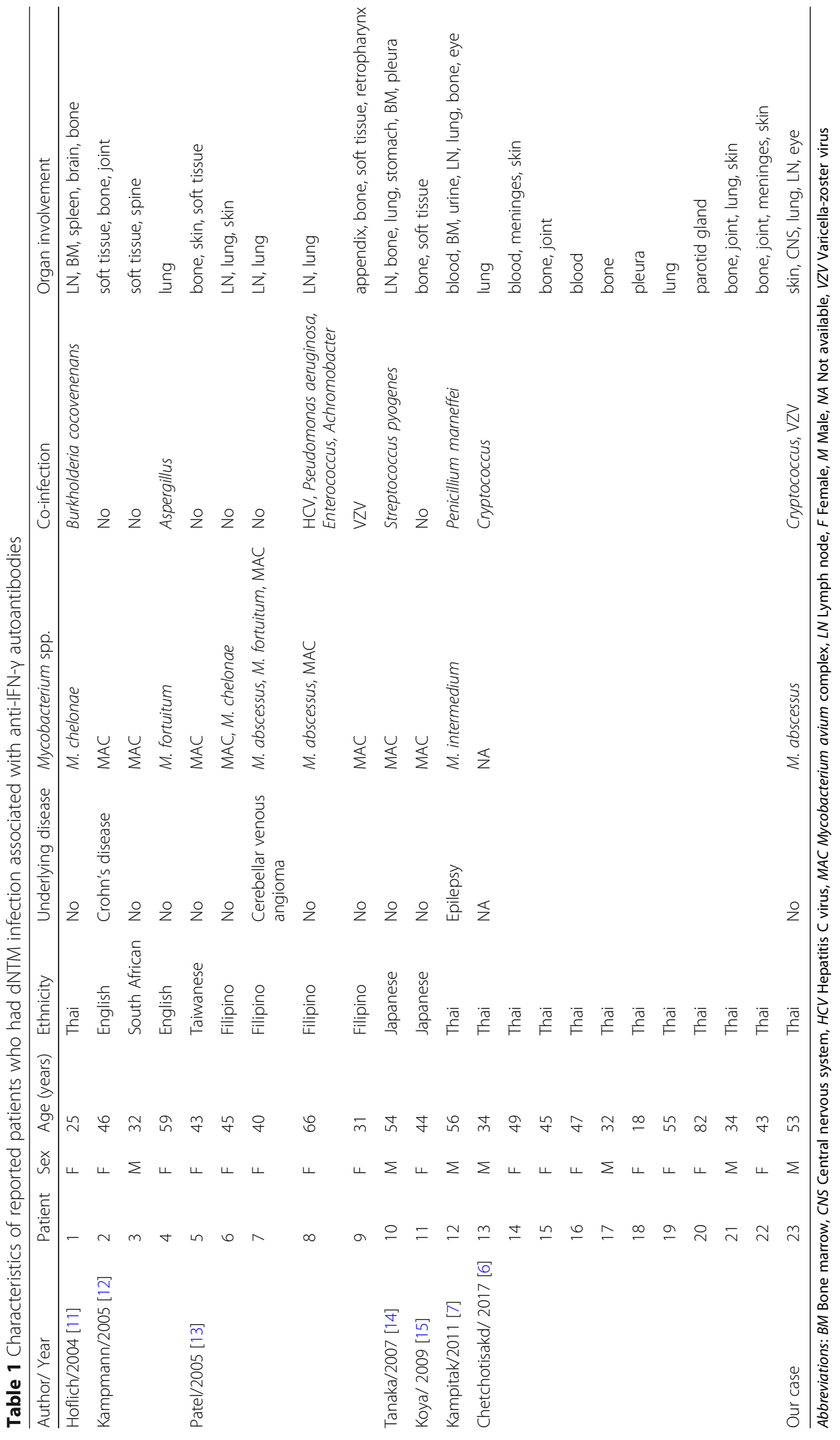


of Janus kinase (Jak1 and Jak2) followed by phosphorylation and dimerization of STAT1, and then it moves to the nucleus to initiate transcription of IFN- $\gamma$ and subsequent production of IFN- $\gamma$ [3]. Genetically inherited disorders of the IFN- $\gamma$ pathway lead to overwhelming infections by intracellular pathogens, such as Cryptococcus, VZV, and nontuberculous mycobacteria, which is similar to the etiology in our case.

Additionally, the majority of patients with auto-IFN- $\gamma$ AAbs were reported to be Southeast Asians [1, 2, 4-8], which is strongly suggestive of an inherited predisposition. These patients were shown to be strongly associated with HLA-DRB1 and HLA-DQB1 [9], which suggests that the development of AAbs to IFN- $\gamma$ may be similar to those observed in other HLA-linked autoimmune diseases. Indeed, the mechanism of the production of autoantibodies to IFN- $\gamma$ remains unclear; however, there are some possible biological explanations. The most possible explanation is that HLA may have an effect on Treg cells during the antigenic presentation process leading to an imbalance in Th1 and Th2, which results in excessive IFN- $\gamma$ following chronic antigenic stimulation [9]. The upregulation of IFN- $\gamma$ can then induce reactive B-cells to produce autoantibodies to IFN- $\gamma$ [10]. If the level of these AAbs is high enough to neutralize IFN- $\gamma$, the patient becomes susceptible to overwhelming infection by intracellular pathogens. Nonetheless, genetic association alone is not sufficient to trigger the disease, and it is likely that autoimmunity in individuals carrying susceptible HLA alleles may be influenced by other, as yet unidentified, factors.

Auto-IFN- $\gamma$ AAbs were reported to be associated with several severe disseminated infections with a prevalence of approximately $90 \%$ in Asian adults with opportunistic infections [1]. Skin manifestation is a frequent characteristic of this syndrome, and about $80 \%$ of cases develop reactive skin conditions and/or unusual infections of the skin [4]. The characteristics of previously reported cases with anti-IFN- $\gamma$ syndromes are summarized in Table 1 $[6,7,11-15]$. Here, we report the case of an anti-IFN- $\gamma$ AAbs patient who presented with unusual cryptococcoma at his left index finger, which was confirmed by skin biopsy and fungal identification. However, reactive skin manifestation, such as neutrophilis dermatosis, was not found in this patient.

In conclusion, this is the first case of triple infection with cryptococcosis, VZV, and INTM in a patient who tested positive for anti-IFN- $\gamma$ AAbs and negative for anti-GM-CSF AAbs. This case will increase awareness and heighten suspicion of these infections in patients with the described presentations and clinical characteristics, and this will accelerate diagnosis and treatment.

\section{Abbreviations}

ADA: Adenosine deaminase; anti-GM-CSF AAbs: Anti-granulocyte-

macrophage colony-stimulating factor autoantibodies; anti-IFN- $\gamma$ AAbs: Anti- interferon-gamma autoantibodies; CD: Cluster of differentiation; CSF: Cerebrospinal fluid; CT: Computed tomography; DNA: Deoxyribonucleic acid; dNTM: Disseminated nontuberculous mycobacterial; HIV: Human immunodeficiency virus; HLA: Human leukocyte antigen; IFN- : Interferongamma; JAK: Janus kinase; RBC: Red blood cell; STAT1: Signal transducer and activator of transcription 1; Th: T helper; VZV: Varicella-Zoster virus; WBC: White blood cell; PA: Posteroanterior; RUL: Right upper lobe; MRI: Magnetic resonance imaging; T2W/FS: T2-weighted fat-saturated; RBCs: Red blood cells

\section{Acknowledgements}

The authors gratefully acknowledge the patient profiled in this report for granting us permission to describe his case.

\section{Authors' contributions}

PR and JS took care of the patient, wrote the draft, and critically revised the manuscript. MC critically revised the manuscript and served as the guarantor. All authors read and approved the final manuscript.

\section{Funding}

There was no funding source for this article.

\section{Availability of data and materials}

All data generated or analyzed during this study are included in this published article.

\section{Ethics approval and consent to participate}

We are exempt from ethical approval from Siriraj Institutional Review Board (SiRB) as it is not required in our hospital for a single case report.

\section{Consent for publication}

The written informed consent was obtained from the patient for publication of this case report and any accompanying images. A copy of the written consent is available for review by the Editor of this journal.

\section{Competing interests}

The authors declare that they have no competing interests.

\section{Author details}

${ }^{1}$ Department of Microbiology, Faculty of Medicine Siriraj Hospital, Mahidol University, Bangkok, Thailand. ${ }^{2}$ Faculty of Medicine Siriraj Hospital, Mahidol University, Bangkok, Thailand. ${ }^{3}$ Division of Infectious Diseases and Tropical Medicine, Department of Medicine, Faculty of Medicine Siriraj Hospital, Mahidol University, 2 Wanglang Road, Bangkoknoi, Bangkok 10700, Thailand.

Received: 8 January 2020 Accepted: 4 March 2020

Published online: 19 March 2020

\section{References}

1. Browne SK, Burbelo PD, Chetchotisakd P, Suputtamongkol Y, Kiertiburanakul S, Shaw PA, Kirk JL, Jutivorakool K, Zaman R, Ding L, et al. Adult-onset immunodeficiency in Thailand and Taiwan. N Engl J Med. 2012;367(8):725-34.

2. Chetchotisakd P, Anunnatsiri S, Nithichanon A, Lertmemongkolchai G. Cryptococcosis in anti-interferon-gamma autoantibody-positive patients : a different clinical manifestation from HIV-infected patients. Jpn J Infect Dis. 2017;70(1):69-74.

3. Knight V, Merkel PA, O'Sullivan MD. Anticytokine autoantibodies: association with infection and immune dysregulation. Basel: Antibodies. 2016;5(1):3. https://doi.org/10.3390/antib5010003.

4. Jutivorakool K, Sittiwattanawong P, Kantikosum K, Hurst CP, Kumtornrut C, Asawanonda P, Klaewsongkram J, Rerknimitr P. Skin manifestations in patients with adult-onset immunodeficiency due to anti-interferon-gamma autoantibody: a relationship with systemic infections. Acta Derm Venereol. 2018;98(8):742-7.

5. Boonchoong P, Vanichanan J, Jutivorakool K. Clinical manifestations, treatment and outcome of nontuberculous mycobacteria (NTM) infection in adult-onset immunodeficiency associated with anti-interferon-gamma autoantibodies in Thai patients: a retrospective descriptive study at the King Chulalongkorn Memorial Hospital. J Infect Dis Antimicrob Agents. 2017;34(3):109-18. 
6. Chetchotisakd P, Kiertiburanakul S, Mootsikapun P, Assanasen S, Chaiwarith $\mathrm{R}$, Anunnatsiri S. Disseminated nontuberculous mycobacterial infection in patients who are not infected with HIV in Thailand. Clin Infect Dis. 2007; 45(4):421-7.

7. Kampitak T, Suwanpimolkul G, Browne S, Suankratay C. Anti-interferon- $\gamma$ autoantibody and opportunistic infections : case series and review of the literature. Infection. 2011;39(1):65-71.

8. Wongkulab P, Wipasa J, Chaiwarith R, Supparatpinyo K. Autoantibody to interferon-gamma associated with adult-onset immunodeficiency in nonHIV individuals in northern Thailand. PLoS One. 2013;8(9):e76371.

9. Pithukpakorn M, Roothumnong E, Angkasekwinai N, Suktitipat B, Assawamakin A, Luangwedchakarn V. HLA-DRB1 and HLA-DQB1 are associated with adult-onset immunodeficiency with acquired antiinterferon-gamma autoantibodies. PLoS One. 2015;10(5):e0128481.

10. Chruewkamlow N, Mahasongkram K, Pata S, Chaiwarith R, Salee P, Supparatpinyo K. Immune alterations in patients with anti-interferon- $\gamma$ autoantibodies. PLoS One. 2016;11(1):e0145983.

11. Hoflich C, Sabat R, Rosseau S, Temmesfeld B, Slevogt H, Docke WD, Grütz G, Meisel C, Halle E, Göbel UB, et al. Naturally occurring anti-IFN- $\gamma$ autoantibody and severe infections with Mycobacterium chelonae and Burkholderia cocovenenans. Blood. 2004;103(2):673-5.

12. Kampmann B, Hemingway C, Stephens A, Davidson R, Goodsall A, Anderson S, Nicol M, Schölvinck E, Relman D, Waddell S, et al. Acquired predisposition to mycobacterial disease due to autoantibodies to IFN-gamma. J Clin Invest. 2005;115(9):2480-8.

13. Patel SY, Ding L, Brown MR, Lantz L, Gay T, Cohen S, Martyak LA, Kubak B, Holland SM. Anti-IFN-gamma autoantibodies in disseminated nontuberculous mycobacterial infections. J Immunol. 2005;175(7):4769-76.

14. Tanaka Y, Hori T, Ito K, Fujita T, Ishikawa T, Uchiyama T. Disseminated Mycobacterium avium complex infection in a patient with autoantibody to interferon-gamma. Intern Med. 2007;46(13):1005-9.

15. Koya T, Tsubata C, Kagamu H, Koyama K, Hayashi M, Kuwabara K, Itoh T, Tanabe Y, Takada T, Gejyo F. Anti-interferon-gamma autoantibody in a patient with disseminated Mycobacterium avium complex. J Infect Chemother. 2009;15(2):118-22.

\section{Publisher's Note}

Springer Nature remains neutral with regard to jurisdictional claims in published maps and institutional affiliations.

Ready to submit your research? Choose BMC and benefit from:

- fast, convenient online submission

- thorough peer review by experienced researchers in your field

- rapid publication on acceptance

- support for research data, including large and complex data types

- gold Open Access which fosters wider collaboration and increased citations

- maximum visibility for your research: over $100 \mathrm{M}$ website views per year

At $\mathrm{BMC}$, research is always in progress.

Learn more biomedcentral.com/submissions 